\title{
European Study Tour Applications Of Experiential Learning Processes In Marketing Education
}

Ed Petkus, Jr., Ramapo College of New Jersey

\begin{abstract}
This article reports on an application of Kolb's $(1981 ; 1984)$ experiential learning cycle in the context of international marketing education. Two study tours, in which International Marketing students at a U.S. college visited various cities in Europe, are described, with an emphasis on the ways in which differences in the structure of the tours may have affected learning outcomes. Implications of these outcomes for the development of international learning experiences, and for future research in this area, are discussed.
\end{abstract}

Keywords: marketing education; experiential learning; international education

\section{INTRODUCTION}

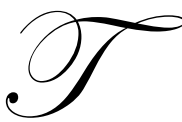

he emerging importance of experiential education in the marketing curriculum is well-documented in the recent marketing education literature (e.g., Ferrell \& Buchanan 2006; Hagenbuch 2006; Klink \& Athaide 2004; Peterson \& Albertson 2006; Reibstein 2006). International and intercultural education is perhaps considered to be equally as important (e.g., Burton 2005; Jones 2003; Kwok, Arpan, \& Folks 1994; Munoz, Wood, \& Cherrier 2006). This article, seeking to integrate these two areas of marketing education, reports on an application of experiential learning processes in the international marketing education context.

Specifically, the paper reports on the experiential learning processes implemented during two study tours in which International Marketing students at a U.S. college visited Europe in 2006. First, a descriptive overview of the two study tours will be presented, with an emphasis on comparison and contrast in the structure and execution of the two experiences. Second, the paper discusses the ways in which the study tours applied Kolb's $(1981 ; 1984)$ experiential learning cycle. Finally, the outcomes and their implications for the development of future international learning experiences are discussed, including specific recommendations for marketing educators.

\section{OVERVIEW OF THE STUDY TOUR EXPERIENCES}

The study tour experiences to be discussed in this article were undertaken in the winter and spring of 2006. For purposes of this article, the two study tours will be designated as ST-A and ST-B. ST-A (February 24 through March 5, 2006) was planned and organized beginning in spring 2005. The three faculty involved (two Management professors and one from Marketing) worked with consultants from a commercial tour operator to compile and organize the itinerary and the corresponding learning experiences. The participants included undergraduate business students at a small, liberal-arts college in the mid-Atlantic region of the U.S. The students of interest (six for ST-A, and five for ST-B) had all completed the International Marketing course during the previous fall semester (2005).

ST-A included the following scheduled tours and visits:

- Munich, Germany: lecture on German re-unification by German political scientist; concentration camp at Dachau; Paulaner Brewery 
- Zurich, Switzerland: formal guided walking tour of business/retail district; lecture by chairman of Swiss Tourism Board on the evolution of the Swiss tourism marketing campaign; lecture by representative of Swiss-American Chamber of Commerce on potential for U.S.-Swiss free-trade agreement

- Strasbourg, France: guided tour of cathedral, including formal discussion of relationship between church and commercial dynamics; tour of European Union Parliament and corresponding lecture; tour of Rene Barth winery in Bennewihr and discussion of Alsatian wine industry business/marketing dynamics

The general theme of ST-A was the business/marketing dynamics of the European Union, including, for contrast, any effects of Swiss neutrality on the marketing dynamics of that country. In addition to the scheduled experiences, free time was built into each day so that students could undertake more spontaneous activities that would provide further immersion in the cultural milieus of the various locations. The students were encouraged to undertake their daily activities in the spirit of ethnographic or participant observation research, which had been discussed in the International Marketing course.

ST-B, by contrast, involved less scheduled, formal learning experiences than did ST-A. ST-B, which ran from May 22-June 2, 2006, consisted of visits to Paris, France; Amsterdam, The Netherlands; and Hamburg and Berlin, Germany. In contrast to ST-A, ST-B was not designed specifically for business students; indeed, the two faculty representatives were from Marketing (the same professor from ST-A) and Chemistry. Upon arrival in each of the cities, the students (who numbered 19 all together, including the five International Marketing students) were taken on a bus tour followed by an extensive walking tour. The purpose of these tours was to orient the students to the basic geography and cultural highlights of the city in order to facilitate their own exploration. In addition, basic historical information was shared with the students, with the intent of providing context for their experiences.

\section{APPLICATION OF KOLB'S EXPERIENTIAL LEARNING CYCLE}

Kolb's $(1981$; 1984) experiential learning cycle has previously been applied in the marketing education literature in the contexts of team-based learning (Bobbitt, Inks, Kemp, \& Mayo 2000), the structure of in-class activities (Hamer 2000), and service learning (Hagenbuch 2006; Petkus 2000). Kolb's cycle involves four distinct yet interrelated phases. In the concrete experience phase, the learner engages rationally, sensorially, and/or emotionally in some activity. The reflective observation phase involves elaboration, discussion, and integration of the observations realized in the concrete experience phase. Next, theoretical and/or conceptual infusion occurs in the abstract conceptualization phase. Finally, in the active experimentation phase, the learner applies the various aspects of the first three phases, testing theories and concepts in real-world contexts.

For both study tours, the students involved were seeking two-credits of independent study related to the International Marketing course that they had completed in the previous Fall semester. The formal requirements for the Independent Study course were (1) a detailed journal (Moncrief, Shipp, \& Lamb 1995) designed to facilitate the concrete experience and reflective observation phases, and (2) an integrative research paper, designed to demonstrate the application of the abstract conceptualization and active experimentation phases. In the following sections, the particular application of each of these phases, with respect to both of the study tours, will be discussed, including a summary of the learning outcomes reflected in the students' journals and research papers.

\section{Concrete Experience}

ST-A and ST-B shared many of the same types of concrete experiences. All students had been familiarized with the basics of ethnographic and participant observation research, and they were reminded to undertake their everyday activities with the mindset of "a good way to learn about international marketing is to be an international consumer." With that framework in mind, students on both study tours were encouraged to seek a variety of retail and service experiences. Retail experiences included dining, shopping, and entertainment; service experiences included transportation and accommodations (and, in one case, a tattoo in Berlin). Students were also encouraged to immerse themselves in the cultural offerings of the cities, within the constraints of time, energy, and money. Finally, in making their free-time choices, students were encouraged to supplement the standard "tourist" experiences with as many "local" experiences as possible (always keeping safety in mind, of course). 
However, as discussed earlier, the concrete experience phase for ST-A was distinguished from that of ST-B by the formal tours, lectures, and visits to businesses. While it could be argued that these experiences were not as "ethnographic" as the more informal, free-time experiences, they nonetheless fit within the concrete experience phase of Kolb's cycle.

For both tours, journal entries for the concrete experience phase were intended to be as descriptive as possible, with a focus on the details of the daily experiences. Students on ST-A included any notes that they took from the formal lectures and visits in the concrete experience part of their journals. The students' journals were reviewed after the first day, and students whose entries lack sufficient detail were encouraged to include more details. For example, regarding dining experiences, most students were more likely at first to report merely what they'd eaten and drank, and perhaps the details of their experience dealing with the language. They were encouraged to attend to and report more varied aspects of their experiences, such as the atmosphere, observations of other customers (especially those who seemed to be locals), service interactions, and even the lavatories. After the first few days, the level of detail reported among all the students improved greatly, and the concrete experience part of the journals was reviewed less regularly.

\section{Reflective Observation}

Beginning with the second day, students were to begin to make the kinds of integrative connections and elaborations that are characteristic of the reflective observation phase. Structurally, students were to include a separate "reflective observation" section in their journals. This section was to be written each day after the concrete experience section was completed. (However, by the middle of ST-A, several students began to combine these two sections, weaving their reflective connections seamlessly into their descriptive details. This worked well enough that it was offered as an option for the journal work in ST-B; indeed, several students structured their entire journals this way, while the rest maintained separation between the two phases.)

There were two main types of reflective observations that the students offered in their journals. First, students would discuss patterns in their experiences. For example, one student noticed patterns in the passive nature of the retail salespeople in German stores. Second, students discussed comparisons and contrasts with the types of marketing and consumer experiences they tend to have in the U.S. For example, most of the students discussed the amount of "American" businesses and products that they observed in a given city, area, or even store. Students also reported on cultural differences that these experiences embodied (e.g., differences in the nature of the offerings at U.S. fast food restaurants, differences in product mixes at American clothing retailers, etc.).

While the reflective observations that students offered were interesting and rich for both tours, those associated with ST-A did appear to be more robust and scholarly than those of ST-B. Of course, this assertion is limited by the fact that these comparisons do not involve the same students. However, the difference that was observed seemed to be a function of the formal tours and business visits that were included in ST-A, which may have given students more "ingredients" on which to reflect. For example, the first night's lecture in Munich on the dynamics of German re-unification provided an important, immediate context in which the rest of the time in Germany could be encased. Indeed, almost all ST-A students mentioned the lecture at least once in their reflective observations. While the faculty involved did their best to provide similar contexts in ST-B, the special gravitas of the lecture from an actual German scholar in ST-A likely carried far more weight and had far more credibility. A similar effect was observed for all of the formal tours and visits during ST-A.

\section{Abstract Conceptualization}

For both study tours, the abstract conceptualization phase required students to make connections between the material that they had generated in their journals (concrete experience and reflective observation) and the concepts they had learned in their International Marketing course (and, generally, from any of their previous coursework). These connections were reported in a seven- to ten-page paper. While the papers were not due until several weeks after the tour, students were encouraged to make notes during the tour that would assist in the later preparation of the conceptualization report. 
As in the reflective observation phase, there seemed to be a difference in learning outcomes between ST-A and ST-B. Specifically, the ST-A students overall generated more robust conceptual connections (for example, references to cultural dynamics theories, standardization vs. customization, political/legal effects on trade based on the European Parliament presentation, etc.). Again, because any comparison of the two tours does not involve the same students, there are limitations to the degree to which these observations can be generalized. Nonetheless, it appears that the formal "academic" aspects of the ST-A experience set a tone for a more scholarly approach to the effort and resulted in more integrative learning outcomes.

Finally, while the ST-A papers were a bit stronger than those of ST-B, the overall abstract conceptualization results across both tours were generally disappointing. It was difficult to get students to go beyond basic comparisons and contrasts among U.S. marketing dynamics and U.S. consumer experiences and those they experienced on the tours (characteristic of the reflective observation phase). This suggests that even more formalization and structure regarding theoretical and conceptual application could result in an even stronger learning experience.

\section{Active Experimentation}

Of all the stages of Kolb's learning cycle, active experimentation was the least-applied, because, technically, students would actually have to go on and work in the international marketing context in order to actually apply their knowledge. Therefore, this discussion will focus on the potential for students to "close the loop" of Kolb's cycle through active experimentation.

In addition to the abstract conceptualizations in their final paper, students were required to address the ways in which, given the opportunity and resources, they would most like to apply the knowledge they had gained from their study tour experience. Specifically, they were to discuss which of the cities visited they would most like to work in, what industries appealed to them, and how they would apply what they had learned. This "virtual" application at least afforded students the opportunity to understand the experiential learning cycle in its entirety.

The learning outcomes associated with this requirement were generally strong. However, again, the ST-A students provided more detail and insight than those in ST-B, and were better able to justify their assertions with specific examples from their study abroad experience.

When practical, an ideal way to actually "close the loop" of Kolb's cycle would be for students to undertake a formal applicative learning experience such as an international internship experience (Toncar \& Cudmore 2000). Toncar and Cudmore report on an international internship model that involves supervised work experience, is relatively short (six weeks or so) compared to a typical semester abroad experience, and has the potential to attract revenue for the institution. Outcomes for students include personal growth, a broadening of personal perspective and empathy with respect to world cultures, and even better performance in regular academic settings.

\section{RECOMMENDATIONS FOR MARKETING EDUCATORS}

Despite the limitations associated with comparing the two study tours, the applications of Kolb's experiential learning cycle discussed herein provided a solid basis for developing recommendations for marketing educators. Figure One summarizes these recommendations in the context of Kolb's cycle.

In the concrete experience phase, the adoption of an enthographic or participant observation model worked well in generating rich, meaningful experiences. Formal tours, lectures, and business visits appeared to provide the most meaningful experiences. In the reflective observation phase, it was important to emphasize critical reflection, identification of patterns, and comparison/contrast. Also, learning outcomes appeared to be enhanced by maintaining a balance between structure and spontaneity. The reader will note that this paper has referred several times to "encouraging" the students to do certain things; needless to say, such advice is not always heeded. A more 
explicit structure could help broaden and deepen the degree of integration and elaboration; however, too much structure might diminish the level of spontaneity and creativity, so a balance should be sought.

Active faculty engagement with the students appeared to enhance the outcomes of the abstract conceptualization phase. The small number of students involved in the study tours was a distinct advantage in generating a meaningful learning experience. On both tours, faculty were able to actively engage with the students as a group and individually throughout the experience, which was especially advantageous in the development of the abstract conceptualization aspect of the learning experience. Such richness would certainly be more challenging with larger groups of students and/or a larger student-to-faculty ratio. Also, it is recommended that faculty require certain specific theoretical and/or conceptual contexts to be addressed.

Finally, when practical, any opportunity for students to "close the loop" be engaging in the active experimentation phase of Kolb's cycle should be pursued. However, if such direct opportunities are not possible, the "virtual" application described herein can act as a reasonable substitute, giving students a chance to at least think through and discuss the potential application of their learning outcomes.

In general, by structuring the two study tour learning experiences as applications of Kolb's experiential learning cycle, the academic aspects of the study abroad experience were significantly enhanced. As detailed in the previous sections, this effect of the experiential learning cycle application was clearly more pronounced in ST-A, apparently due to the incorporation of formal tours, lectures, and visits to businesses. However, more extensive study would need to be undertaken to investigate this phenomenon further, and so this article will conclude with a call for further research, both conceptual and empirical, into this important area of international marketing education.

\section{REFERENCES}

1. Burton, D. (2005), New Course Development in Multicultural Marketing, Journal of Marketing Education 27(2): 151-63.

2. Ferrell, L., and Buchanan, M. A. (2006), Torch Awards for Marketplace Ethics: Providing Students "Hands On" Experience with Marketing Ethics, Marketing Education Review 16 (Spring): 47-51.

3. Hagenbuch, D. J. (2006), Service Learning Inputs and Outcomes in a Personal Selling Course, Journal of Marketing Education 28(1): 26-34.

4. Jones, W. H. (2003), Over the Wall: Experiences with Multicultural Literacy, Journal of Marketing Education 25(3): 231-40.

5. Klink, R. P., and Athaide, G. A. (2004), Implementing Service Learning in a Principles of Marketing Course, Journal of Marketing Education 26(2): 145-53.

6. Kolb, D. A. (1981), Learning Styles and Disciplinary Differences, in A.W. Chickering and Associates, The Modern American College, San Francisco: Jossey-Bass, 37-75.

$7 . \quad$ (1984), Experiential Learning: Experience as the Source of Learning and Development, Englewood Cliffs, NJ: Prentice-Hall.

8. Kwok, C. C. Y., Arpan, J., and Folks. W. R. (1994), A Global Survey of International Business Education in the 1990's, Journal of International Business Studies 25(3): 605-23.

9. Moncrief, W. C., Shipp, S. H., and Lamb, Jr., C. W. (1995), Student Journal Writing in an International Setting, Journal of Marketing Education 17(Summer): 71-80.

10. Munoz, C. L., Wood, N. T., and Cherrier, H. (2006), It's A Small World After All: Cross-Cultural Collaborative Exercises, Marketing Education Review 16(Spring): 53-57.

11. Peterson, R. M., and Alberston, D. E. (2006), Running a Micro Business in Marketing Class: Experiential Learning Right Out of the Gate, Marketing Education Review 16(Spring): 105-109.

12. Petkus, Jr., E. (2000), A Theoretical and Practical Framework for Service-Learning in Marketing: Kolb's Experiential Learning Cycle, Journal of Marketing Education 22(1): 64-70.

13. Reibstein, D. (2005), Learning by Doing, International Journal of Marketing Education 1(1): 113-128. 
14. Toncar, Mark F., and Brian V. Cudmore (2000), The Overseas Internship Experience, Journal of Marketing Education, 22(1), 54-63.

Figure One:

Recommendations For Marketing Educators For Application Of Kolb's Experiential Learning Cycle In Study Abroad Context

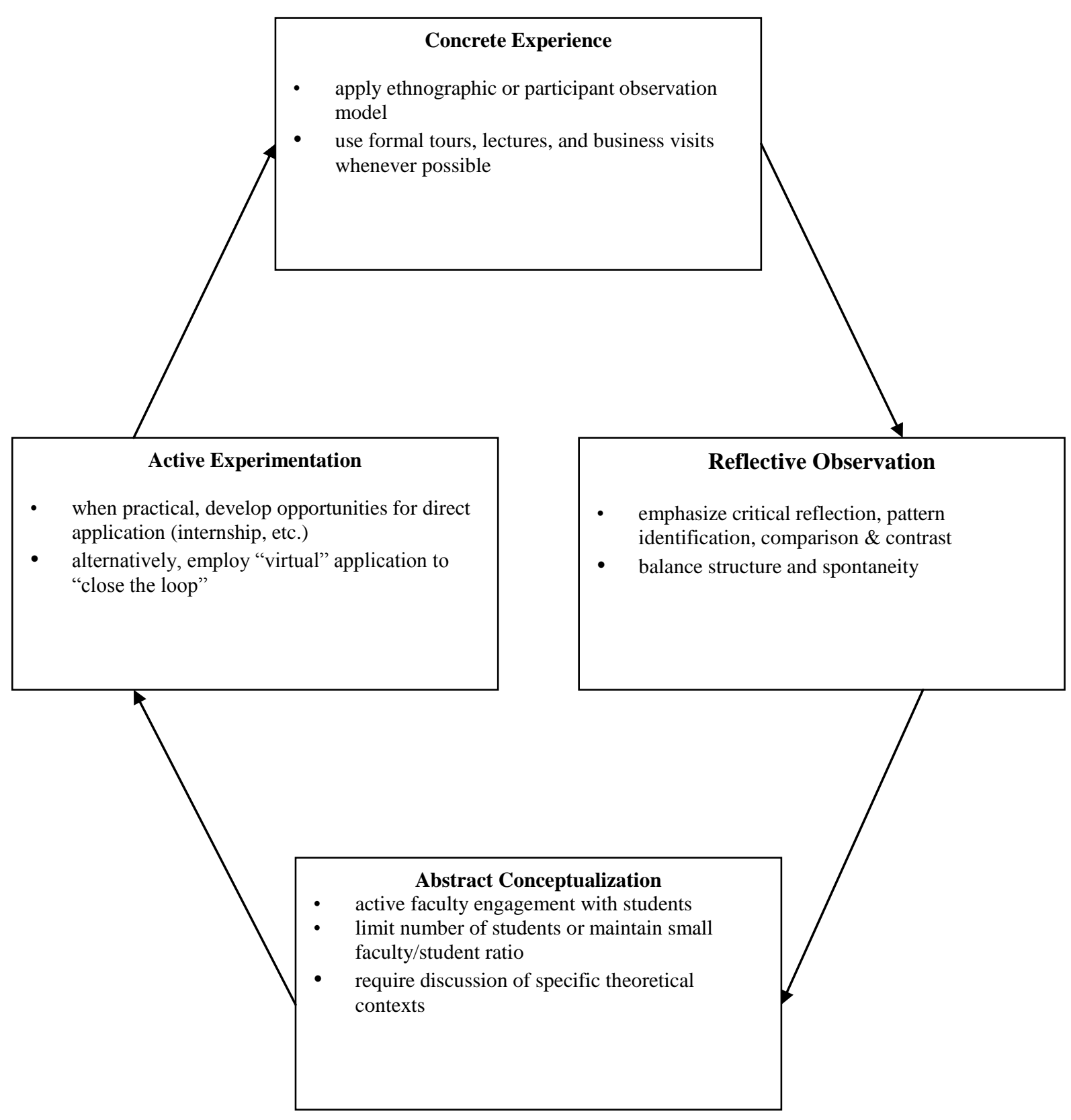

